lớp cơ ngoài của niệu đạo bên trong một vỏ xơ đệm giả và gây ra triệu chứng lâm sàng. Trong khi đó phì đại quanh niệu đạo xuất phát từ phần sâu vùng tuyến quanh cơ thắt niệu đạo. Loại phì đại này có thể dần đến tắc nghẽn đường ra của bàng quang do chèn ép bàng quang và làm dịch chuyển vùng tam giác cổ bàng quang lên phía trên. Còn dạng phì đại có cuống sẽ lồi vào lòng bàng quang gây cơ chế tắc nghẽn kiểu van đóng mở.

Trong nghiên cứu này chúng tôi nhận thấy không có khác biệt có ý nghĩa thống kê về điểm IPSS trung bình và QoL trung bình giữa nhóm $B N$ có hình thái TTL loại 1, 2, 3 (không có cuống hoặc phì đại vùng sau tam giác cổ bàng quang) so với loại 5, 6, 7 (có cuống hoặc phì đại vùng sau tam giác cổ bàng quang) (Bảng 5 ).

PĐLTTTL thường xảy ra ở vùng chuyển tiếp hai bên, dẫn đến tăng kích thước vùng chuyển tiếp, đè đẩy gây hẹp niệu đạo $T T L$, dẫn đến triệu chứng tắc nghẽn đường tiểu. Khi có biểu hiển tăng sản ở vùng trung tâm, có thể dẫn đến lî̀i vùng trung tâm vào lòng bàng quang. Trên thực hành lâm sàng, phần vùng trung tâm lồi vào lòng bàng quang được định nghĩa là khoảng cách từ vùng đỉnh của phần TTL lồi vào bàng quang đến nền bàng quang trên lát cắt đứng dọc.

Trong nghiên cứu của chúng tôi có $23 \mathrm{BN}$ TSLTTTL lồi vào lòng bàng quang. Trong số các trường hợp có lồi vào lòng bàng quang, lồi độ 3 (>10mm) chiếm đa số với tỉ lệ 69,6\% (Bảng 6). Có mối tương quan yếu giữa mức độ lồi vào lòng bàng quang với tổng điểm IPSS trong nghiên cứu của chúng tôi với chỉ số tương quan $\mathrm{R}^{2}=0,017$ và chỉ số tương quan Pearson rearson $=$ 0,131 nhưng không có ý nghĩa thống kế $(p>0,05)$.

\section{KẾT LUẬN}

Lựa chọn bệnh nhân can thiệp nút động mạch tuyến tiền liệt phụ thuộc nhiều yếu tố bao gồm cả triệu chứng lâm sàng và các xét nghiệm sinh hóa, hình ảnh với mục đích đánh giá chính xác tình trạng bệnh. Trong đó, cộng hưởng từ là phương pháp chẩn đoán hình ảnh có giá trị để đánh giá thể tích, hình thái, tính chất nhu mô tuyến trước can thiệp.

\section{TÀI LIÊU THAM KHẢO}

1. Garraway, W.M., G.N. Collins, and R.J. Lee, High prevalence of benign prostatic hypertrophy in the community. Lancet, 1991. 338(8765): p. 469-71.

2. Kirkham, A.P., et al., Prostate MRI: who, when, and how? Report from a UK consensus meeting. Clin Radiol, 2013. 68(10): p. 1016-23.

3. Wasserman, N.F., et al., Use of MRI for Lobar Classification of Benign Prostatic Hyperplasia: Potential Phenotypic Biomarkers for Research on Treatment Strategies. AJR Am J Roentgenol, 2015. 205(3): p. 564-71.

4. Dmochowski, R.R., Bladder outlet obstruction: etiology and evaluation. Rev Urol, 2005. 7 Suppl 6: p. S3-S13.

5. Shapiro, E., et al., The relative proportion of stromal and epithelial hyperplasia is related to the development of symptomatic benign prostate hyperplasia. J Urol, 1992. 147(5): p. 1293-7.

6. Hansford, B.G., et al., Dynamic contrastenhanced MR imaging features of the normal central zone of the prostate. Acad Radiol, 2014. 21(5): p. 569-77.

7. Shin, S.H., et al., Defining the degree of intravesical prostatic protrusion in association with bladder outlet obstruction. Korean J Urol, 2013. 54(6): p. 369-72.

8. Topazio, L., et al., Intravescical prostatic protrusion is a predictor of alpha blockers response: results from an observational study. BMC Urol, 2018. 18(1): p. 6.

\title{
HIÊU QUẢ ĐIỀU TRI ĐAU VÙNG CỔ GÁY DO THOÁI HÓA CộT SỐNG BẰNG PHƯƠNG PHÁP CẤY CHİ KẾT HỢP CHIẾU ĐÈN TẦN PHỔ
}

\section{TÓM TẮT}

Mục tiêu: Đánh giá hiệu quả điều trị đau vùng cổ gáy do thoái hóa cột sống bằng cấy chỉ kết hợp chiếu đèn tân phổ. Đối tượng và phương pháp: 60 bệnh

\footnotetext{
${ }^{1}$ Bệnh viện Châm cứu Trung ương,

${ }^{2}$ Viên Y hoc cổ truyền Quân đồi

Chịu trách nhiệm chính: Nguyễn Vinh Quốc

Email: quocnguyenvinh@gmail.com

Ngày nhận bài: 26/7/2021

Ngày phản biên khoa hoc: 25/8/2021

Ngày duyệt bài: 18/9/2021
}

\section{Nguyễn Đức Minh ${ }^{1}$, Nguyễn Vinh Quốc ${ }^{2}$}

nhân tuổi trên 30 được chẩn đoán đau vùng cổ gáy do thoái hóa cột sống, không phân biệt giới tính, nghề nghiêp, tình nguyênn tham gia nghiển cứu. Nhóm đối chứngđiều trị bằng xoa bóp bấm huyệt kết hợpchiếu đèn tần phổ, nhóm nghiên cứu điều trị như nhóm đối chứng kết hợp cấy chỉ. So sánh kết quả sau 20 ngày điều trị. Kết quả: Cấy chỉ kết hợp chiếu đèn tần phổhiệu quả trong điêu trị đau vùng cổ gáy do thoái hóa cột sống, $90 \%$ đạt hiệu quả tốt và khá. Biên độ hoat động cột sống cổ, mức độ đau và mức độ hạn chể sinh hoạt hàng ngày NDI cải thiện tốt hơn có ý nghĩa so với trước điều trị và tốt hơn so với nhóm đối chứng. Kết luận: Cấy chỉ kết hợp chiếu đèn tần 
phổhiệu quả tốt trong điều trị đau vùng cổ gáy do thoái hóa cột sống.

Tứ khóa: Đau vùng cổ gáy, cây chỉ.

\section{SUMMARY}

THE EFFECT OF IMPLANTATION COMBINED WITHELECTROMAGNETIC SPECTRUM THERAPY DEVICEON TREATING NECK PAIN WITH CERVICAL SPONDYLOSIS

Objective: To evaluate effect of implantation combined with Electromagnetic Spectrum Therapy Device (TDP) on treament of neck pain with cervical spondylosis. Subjects and methods: 60 volunteered patients aged over 30 was diagnosed with neck pain by cervical spondylosis, regardless of gender or occupation, were participated in the study. The control group combined using acupressure massage with TDP, while the study group treated the same as the control group in combination with thread implant. Comparing the results after 20 days treatment. Result: The spondylosis of neck pain treating method by using the combination of implantation with spectrum lamp irradiationworked efficiency, $90 \%$ rate of good and effective results. The amplitude of activity of the cervical spine, pain level and the NDI score improved better than before treatment and better than control group, difference is statistically significant. Conclusion: The treating method using implantation combined with TDPshow pleasing outcome during treatment for the neck pain with cervical spondylosis.

Keyword: Neck pain, thread implant.

\section{I. ĐĂT VẤN ĐỀ}

Đau vùng cổ gáy (hội chứng cổ vai cánh tay) do thoái hóa cột sống (THCS) là là bệnh lý khá phổ biến, thường gặp trong xã hội hiện đại, chỉ đứng thứ 2 sau THCS thắt lưng và đang có xu hướng trẻ hóa[1], [2], [3]. Bệnh ít nguy hiểm tới tính mạng nhưng gây ảnh hưởng không tốt tới chất lượng cuộc sống của người bệnh[3],[4], [5]... Do vậy điều trị hiệu quả bệnh lý này đang là mối quan tâm nghiên cứu của các thây thuốc. Y học cổ truyền (YHCT) đã thể hiện được những ưu việt trong điều trị các chứng đau mạn tính nói chung và đau vùng cổ gáy do THCS nói riêng, trong đó có các kỹ thuật điều trị không dùng thuốc[3],[4],[5]. Cấy chỉ là phương pháp điều trị bằng đưa chỉ tự tiêu vào huyệt vị của hệ kinh lạc nhằm duy trì sự kích thích liên tục tại huyệt, qua đó tạo nên tác dụng điều trị như châm cứu. Cấy chỉ đã được nhiều nghiên cứu áp dụng trong điều trị và mang lại hiệu quả tích cực[5], [6]... Chiếu đèn tần phổ là phương pháp vật lý có tác dụng giảm đau, giãn cơ, tăng tuần hoàn vùng tác động, giảm các triệu chứng viêm cũng được nhiều thầy thuốc $Y$ học hiện đại sử dụng trong trị liệu bệnh lý cột sống[7]. Để có cơ sở khoa học khẳng định hiệu quả của phương pháp, nghiển cứu được thực hiện nhằm mục tiêu đánh giáhiệu quả điều trị đau vùng cổ gáy do THCS thể can thận hư kết hợp phong hàn thấp bằng cấy chỉ kết hợp chiếu đèn tần phổ.

\section{II. ĐỐI TƯỢNG VÀ PHƯƠNG PHÁP NGHIÊN CỨU \\ 2.1. Phương tiện nghiên cứu}

- Phác đồ huyệt cấy chỉ: Giáp tích C2-C7, Thiên trụ, Kiên tỉnh, Phong trì, Phong môn, Thận du, Can du, Đại trữ, Mệnh môn, Khí hải, Quan nguyên[8].

- Đèn tân phổ CQ-BS8 do Trung Quốc sản xuất; thước đo thang điểm VAS (Visual analogue scale); thước đo tầm vận động cột sống cổ.

- Kim cây chỉ vô trùng dùng 1 lần, chỉ catgut số 3-4 vô khuẩn; lọ nút mài, pince, bông, cồn $70^{\circ}$... cần thiết phục vụ yêu cầu kỹ thuật[8].

2.2. Đối tượng nghiên cứu. 60 bệnh nhân (BN) tuổi trên 30 được chẩn đoán đau vùng cổ gáy do THCS, phù hợp chứng Tý thể can thận hư kết hợp phong hàn thấp theo YHCT[2]; khồng phân biệt giới tính, nghề nghiệp, tình nguyện tham gia nghiên cứu. Điều trị tại Bệnh viện Châm cứu Trung ương và Bệnh viện Tuệ Tỉnh - Học viện $Y$ dược học cổ truyền Việt Nam từ tháng $7 / 2019$ đến tháng 9/2020. Không đưa vào nghiên cứu những trường hợp ung thư, chấn thương, dị dạng cột sống, bệnh lý ngoài cột sống gây đau.

2.3. Phương pháp nghiên cứu. Thử nghiệm lâm sàng tiến cứu, so sánh kết quả trước và sau điều trị có đối chứng. Chọn mẫu có chủ đích theo phương pháp ghép cặp đảm bảo tương đồng về tuổi, giới tính, nghề nghiệp, thời gian mắc bệnh. Các $B N$ được chia thành 2 nhóm, mỗi nhóm 30 BN:

- Nhóm đối chứng (NĐC): được chiếu đèn tần phổ tại vùng đau thời gian 30 phút, sau đó tiến hành xoa bóp bấm huyệt (thực hiện các động tác từ nhe đến nặng bao gồm day, lăn, bóp, chặt, bấm, ấn, vờn, vận động) vùng cổ, vai, cánh tay bên đau mỗi lần 30 phút[8]. Các kỹ thuật trên áp dụng mỗi ngày 1 lần, liệu trình điều trị 20 ngày.

- Nhóm nghiên cứu (NNC): được điều trị như NĐC kết hợp cây chỉ các huyệt theo phác đồ, quy trình thực hiện kỹ thuật theo hướng dẫn của Bộ Y tế [8]. Thực hiện cây chỉ 2 lần tại thời điểm ngày thứ nhất và ngày thứ 10 của nghiên cứu.

- Chỉ tiêu theo dõi và đánh giá:

+ Đặc điểm chung các BN nghiên cứu: Tuổi, giới tính, nghề nghiệp, thời gian mắc bệnh, đặc điểm tổn thương trên phim Xquang quy ước.

+Hiệu quả điều trị: Đánh giá hiệu quả cải thiện mức độ đau theo thang điểm VAS, mức độ cải thiện tầm vận động cột sống cổ các tư thế cúi, ngửa, nghiêng, xoay bằng thước đo nhân trắc học, mức độ cải thiện hạn chế sinh hoạt 
hàng ngày theo bộ câu hỏi NDI (Neck Disability Index)[1].

Các chỉ tiêu theo dõi được đánh giá tại thời điểm trước điều trị $\left(T_{0}\right)$, sau 10 ngày điều trị $\left(T_{1}\right)$ và sau 20 ngàyđiều trị $\left(\mathrm{T}_{2}\right)$.

- Đánh giá kết quả điều trị chung: so sánh điểm lượng hóa các chỉ tiêu theo dõi lâm sàng trước và sau điều trị, phân thành loại tốt (tổng điểm sau điều trị giảm $>80 \%$ so với trước điều trị); Khá (tổng điểm sau điều trị giảm $61-80 \%$ so với trước điêu trị); Trung bình (tổng điểm sau điều trị giảm 40-60\% so với trước điều trị); Kém (tổng điểm sau điều trị giảm $<40 \%$ so với trước điều trị)[3],[4], [5].

2.4. Xử lý số liệu. Các số liệu được xử lý theo phương pháp thống kê y sinh học bằng phần mềm SPSS 16.0 for Windows. Các thuật toán được áp dụng: tính tỷ lệ phần trăm, tính số trung bình, độ lệch chuẩn, so sánh số trung bình theo thuật toán T-Student.

\section{KẾT QUẢ NGHIÊN CỨU}

3.1. Đặc điểm chung các đối tượng nghiên cứu

Bảng 1. Đắc điểm chung các bênh nhân nghiên cứu

\begin{tabular}{|c|c|c|c|c|c|c|}
\hline \multirow{2}{*}{\multicolumn{2}{|c|}{ Chỉ tiêu }} & \multicolumn{2}{|c|}{$N N C^{(1)}(n=30)$} & \multicolumn{2}{|c|}{$N^{\prime 2}(n=30)$} & \multirow{2}{*}{$\mathbf{p}_{1-2}$} \\
\hline & & Số lượng & Tỷ lệ \% & Số lượng & Tỷ lệ \% & \\
\hline \multirow{5}{*}{ Tuổi } & $\leq 49$ & 11 & 36,66 & 10 & 33,33 & $>0,05$ \\
\hline & $50-59$ & 12 & 40 & 10 & 33,33 & $>0,05$ \\
\hline & $60-69$ & 05 & 16,67 & 07 & 23,34 & $>0,05$ \\
\hline & $\geq 70$ & 02 & 6,67 & 03 & 10 & $>0,05$ \\
\hline & $(X \pm S D)$ & \multicolumn{2}{|c|}{$54,37 \pm 9,65$} & \multicolumn{2}{|c|}{$55,5 \pm 10,79$} & $>0,05$ \\
\hline \multirow{2}{*}{ Giới tính } & Nam & 11 & 36,7 & 12 & 40 & $>0,05$ \\
\hline & Nữ & 19 & 63,3 & 18 & 60 & $>0,05$ \\
\hline \multirow{3}{*}{ Nghề nghiệp } & Lao động chân tay & 7 & 23,33 & 6 & 20 & $>0,05$ \\
\hline & Lao động trí óc & 9 & 30 & 11 & 36,67 & $>0,05$ \\
\hline & Hưu trí & 14 & 46,67 & 13 & 43,33 & $>0,05$ \\
\hline \multirow{3}{*}{$\begin{array}{l}\text { Thời gian } \\
\text { mắc bệnh }\end{array}$} & $<1$ tháng & 7 & 23,33 & 8 & 26,67 & $>0,05$ \\
\hline & $1-3$ tháng & 18 & 60 & 16 & 53,33 & $>0,05$ \\
\hline & $>3$ tháng & 5 & 16,67 & 6 & 20 & $>0,05$ \\
\hline \multirow{3}{*}{$\begin{array}{l}\text { Hình ảnh } \\
\text { Xquang cột } \\
\text { sống cổ }\end{array}$} & Mất đường cong sinh lý & 28 & 93,33 & 29 & 96,67 & $>0,05$ \\
\hline & Mơ, hẹp khe khớp & 17 & 56,67 & 15 & 50 & $>0,05$ \\
\hline & Gai xương & 25 & 83,33 & 23 & 76,67 & $>0,05$ \\
\hline
\end{tabular}

Phần lớn các $B N$ có thời gian mắc bệnh từ 1 tới 3 tháng với biểu hiện tổn thương chủ yếu trên Xquang cột sống cổ là mất đường cong sinh lý, gai xương. Chưa nhận thấy khác biệt giữa các yếu tố tuổi, giới tính, nghề nghiệp, thời gian mắc bệnh và đặc điểm tổn thương Xquang cột sống cổ giữa hai nhóm BN nghiên cứu $(p>0,05)$.

\subsection{Kết quả điêu trị}

Bảng 2. Cải thiện mức độ đau VAS sau điều trị (điểm; $\left.{ }^{\bar{x}} \pm S D\right)$

\begin{tabular}{|c|c|c|c|}
\hline Thời điếm & $\operatorname{NNC}^{(1)}(n=30)$ & $\operatorname{NĐC}^{(2)}(n=30)$ & $\mathbf{p}_{1-2}$ \\
\hline$T_{0}(\mathrm{a})$ & $5,60 \pm 1,19$ & $5,43 \pm 1,17$ & $>0,05$ \\
\hline$T_{1}(b)$ & $3,63 \pm 1,13$ & $4,00 \pm 0,95$ & $>0,05$ \\
\hline $\mathrm{T}_{2}{ }^{(c)}$ & $1,17 \pm 1,11$ & $1,87 \pm 1,16$ & $<0,05$ \\
\hline $\mathrm{p}$ & $\mathrm{p}_{a-b} ; \mathrm{p}_{a-c} ; \mathrm{p}_{\mathrm{b}-\mathrm{c}}<0,05$ & pa-b; $\mathrm{p}_{\mathrm{a}-\mathrm{c} ;} ; \mathrm{p}_{\mathrm{b}-\mathrm{c}}<0,05$ & \\
\hline
\end{tabular}

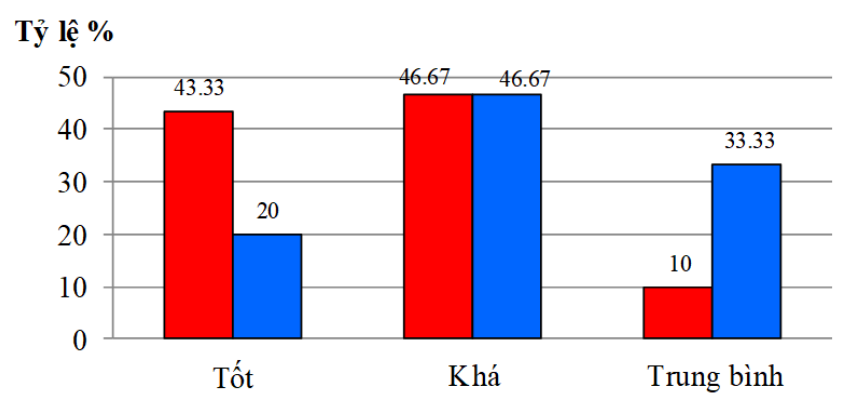

$\square \mathrm{NNC}$

$\square \mathrm{NĐC}$

Biểu đồ 1. Hiệu quả giảm đau sau 20 ngày điều trị

Mức độ đau VAS có xu hướng giảm dần qua các thời điểm theo dỗi ở cả 2 nhóm. Khác biệt tại thời 
điểm trước điều trị $\left(T_{0}\right)$ và sau điều trị $\left(T_{1} ; T_{2}\right)$ khi so sánh cùng nhóm có ý nghĩa thống kê $(p<0,05)$. VAS trung bình sau 20 ngày điều trị ở NNC tốt hơn NĐC với $p<0,05$. Hiệu quả giảm đau sau 20 ngày điều trị đánh giá ở mức độ tốtở NNC (43,33\%), cao hơn NĐC (20\%).

Bảng 3. Cải thiện tầm vận động cột sống cổ sau điều trị (độ; × $\pm S D)$

\begin{tabular}{|c|c|c|c|c|}
\hline Động tác & Thời điếm & $\operatorname{NNC}^{(1)}(n=30)$ & $\operatorname{NDC}^{(2)}(n=30)$ & p1-2 \\
\hline \multirow{3}{*}{ Cúi } & $T_{0}{ }^{(a)}$ & $17,00 \pm 3,56$ & $16,60 \pm 3,57$ & $>0,05$ \\
\hline & $\mathrm{T}_{2}{ }^{(\mathrm{c})}$ & $32,91 \pm 3,52$ & $30,50 \pm 4,37$ & $>0,05$ \\
\hline & $\mathrm{p}_{\mathrm{a}-\mathrm{c}}$ & $<0,05$ & $<0,05$ & \\
\hline \multirow{3}{*}{ Ngửa } & $T_{0}{ }^{(a)}$ & $15,37 \pm 5,36$ & $15,17 \pm 5,81$ & $>0,05$ \\
\hline & $T_{2}{ }^{(c)}$ & $33,73 \pm 5,02$ & $31,17 \pm 5,60$ & $>0,05$ \\
\hline & $\mathrm{p}_{\mathrm{a}-\mathrm{c}}$ & $<0,05$ & $<0,05$ & \\
\hline \multirow{3}{*}{ Nghiêng } & $T_{0}(a)$ & $15,77 \pm 3,90$ & $16,73 \pm 3,62$ & $>0,05$ \\
\hline & $T_{2}{ }^{(c)}$ & $37,83 \pm 5,96$ & $32,31 \pm 4,86$ & $<0,05$ \\
\hline & $\mathrm{pa}_{\mathrm{a}-\mathrm{c}}$ & $<0,05$ & $<0,05$ & \\
\hline \multirow{3}{*}{ Xoay } & $T_{0}{ }^{(a)}$ & $16,93 \pm 3,22$ & $18,70 \pm 3,53$ & $>0,05$ \\
\hline & $\mathrm{T}_{2}{ }^{(\mathrm{c})}$ & $35,23 \pm 6,27$ & $31,93 \pm 5,64$ & $<0,05$ \\
\hline & $\mathrm{pa-c}$ & $<0,05$ & $<0,05$ & \\
\hline
\end{tabular}

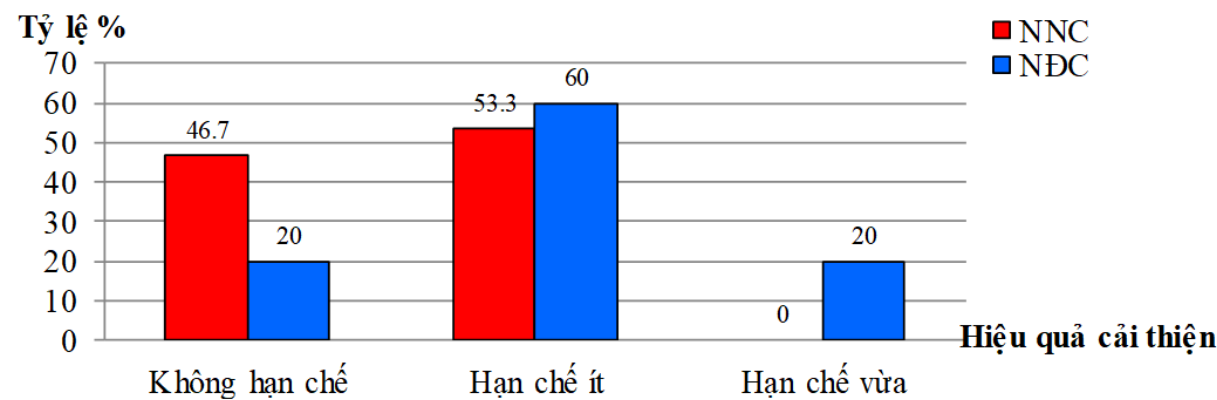

Biểu đồ 2. Hiệu quả cải thiện tầm vận động cột sông cổ sau điều trị

Tầm vận động cột sống cổ các động tác cúi, ngửa, nghiêng, xoay ở 2 nhóm đều cải thiện so với trước điêu trị, khác biệt có ý nghĩa với $p<0,05$. Tầm vận động cột sống cổ các động tác nghiêng, xoay sau 20 ngày điều trị ở NNC tốt hơn NĐC $(p<0,05)$. Hiệu quả cải thiện tầm vận động cột sống cổ sau 20 ngày điêu trị đánh giá ở mức không hạn chế ở NNC (46,7\%), cao hơn NĐC (20\%).

Bảng 4. Cải thiện điểm NDI sau điều trị (điểm; ${ }^{\bar{x}} \pm S D$ )

\begin{tabular}{|c|c|c|c|}
\hline Thời điếm & $\operatorname{NNC}^{(1)}(n=30)$ & $\operatorname{NĐC}^{(2)}(n=30)$ & $\mathbf{p}_{1-2}$ \\
\hline $\mathrm{T}_{0}{ }^{(\mathrm{a})}$ & $19,80 \pm 6,43$ & $19,93 \pm 5,78$ & $>0,05$ \\
\hline $\mathrm{T}_{1}{ }^{\mathrm{b})}$ & $14,17 \pm 6,20$ & $16,07 \pm 5,84$ & $>0,05$ \\
\hline $\mathrm{T}_{2}{ }^{(\mathrm{c})}$ & $7,43 \pm 4,92$ & $11,73 \pm 4,96$ & $<0,05$ \\
\hline $\mathrm{p}$ & Pa-b; $\mathrm{Pa}-c ;^{\prime} \mathrm{p}_{\mathrm{b}-\mathrm{c}}<0,05$ & рa-b; pa-c; pb-c $<0,05$ & \\
\hline
\end{tabular}

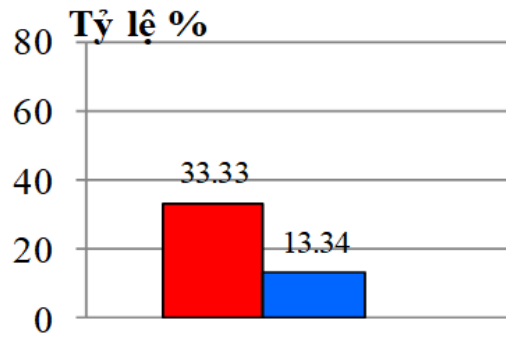

Không hạn chế

\section{$60 \quad 63.33$}

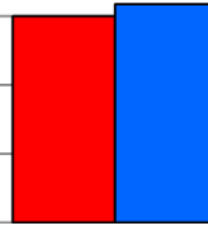

Hạn chế nhẹ

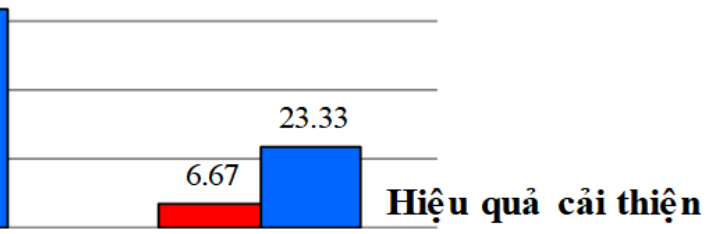

Hạn chế trung bình

Biểu đồ 3. Mức độ cải thiện hạn chế sinh hoạt hàng ngàyNDI sau điều trị

Mức độ hạn chế sinh hoạt hàng ngày NDİải thiệnqua các thời điểm theo dõi ở cả 2 nhóm BNcó ý nghĩa thống kê khi so sánh cùng nhóm $(p<0,05)$. Điểm NDI trung bìnhsau 20 ngày điều trị ở NNC tốt hơn NĐC với $p<0,05$. Chức năng sinh hoạt hàng ngày sau 20 ngày điều trị đánh giá ở mức không hạn chế ở NNC (33,33\%), cao hơn so với NĐC (13,34\%). 


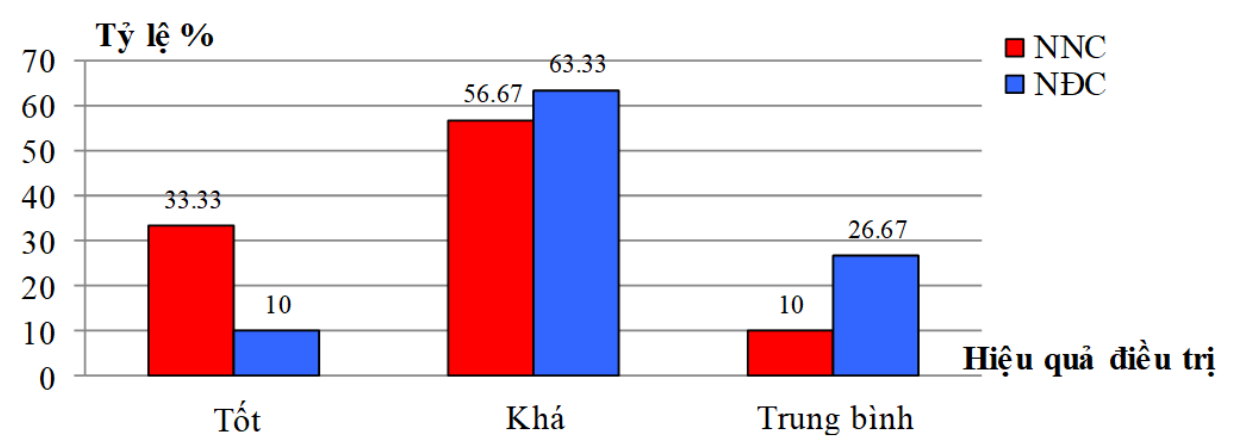

Biểu đồ 4. Kêt quả điều trị chung

Sau điều trị, $90 \%$ BN NNC đạt kết quả tốt và khá, cao hơn có ý nghĩa so với NĐC (73,33\%). Không có trường hợp nào không đáp ứng với điều trị.

3.3. Tác dụng không mong muốn của phương pháp. Trong quá trình điều trî̀, không có trường hợp nào bị bỏng rát, bầm tím, vựng châm, tụ máu, chảy máu, nhiềm khuẩn tại chố.

\section{Bảng 5. Thay đổi tần số mạch, chi số huyêt áp sau điêuu trị $\left({ }^{\times} \pm S D\right)$}

\begin{tabular}{|c|c|c|c|c|}
\hline Chì tiêu & Thởi điếm & $\operatorname{NNC}^{(1)}(n=30)$ & $N^{\prime} C^{(2)}(n=30)$ & p1-2 \\
\hline \multirow{3}{*}{ Mạch (lần/phút) } & $T_{0}{ }^{(a)}$ & $75,03 \pm 3,34$ & $75,37 \pm 3,63$ & $>0,05$ \\
\hline & $\mathrm{T}_{2}{ }^{(c)}$ & $75,27 \pm 2,33$ & $75,13 \pm 2,22$ & $>0,05$ \\
\hline & $\mathrm{Pa}_{\mathrm{a}-\mathrm{c}}$ & $>0,05$ & $>0,05$ & \\
\hline \multirow{3}{*}{$\begin{array}{l}\text { Huyết áp tâm thu } \\
(\mathrm{mmHg})\end{array}$} & $T_{0}{ }^{(a)}$ & $125,04 \pm 8,61$ & $128,71 \pm 18,30$ & $>0,05$ \\
\hline & $\mathrm{T}_{2}{ }^{(c)}$ & $122,67 \pm 7,04$ & $129,57 \pm 9,03$ & $>0,05$ \\
\hline & $P_{a-c}$ & $>0,05$ & $>0,05$ & \\
\hline \multirow{3}{*}{$\begin{array}{l}\text { Huyết áp tâm trương } \\
\qquad(\mathrm{mmHg})\end{array}$} & $\mathrm{T}_{0}{ }^{(\mathrm{a})}$ & $75,67 \pm 7,74$ & $86,7 \pm 6,8$ & $>0,05$ \\
\hline & $\mathrm{T}_{2}{ }^{(c)}$ & $74,00 \pm 5,63$ & $87,8 \pm 7,8$ & $>0,05$ \\
\hline & $\mathrm{Pa-c}$ & $>0,05$ & $>0,05$ & \\
\hline
\end{tabular}

Tần số mach, chỉ số huyết áp trước và sau điều trị ở cả 2 nhóm BN thay đổi không có ý nghĩa thống kê $(p>0,05)$.

\section{BÀN LUÂN}

4.1.Về đặc điểm chung các đối tượng nghiên cứu. Tuổi mắc bệnh trung bình các $\mathrm{BN}$ trong nghiên cứu là $54,37 \pm 9,650$ ơ NNC và 55,5 $\pm 10,79$ ở NĐC, trong đó độ tuổi từ 50-59 chiếm tỷ lệ cao. Kết quả này cho thấy đau vùng cổ gáy do THCS thường gặp ở những đối tượng đang trong độ tuổi lao động, do vậy bệnh ảnh hưởng nhiều tới chất lượng công việc cũng như chất lượng sống của người bệnh, phù hợp với nhận định của nhiều tác giả[3],[4], [5]...Theo YHCT, nữ giới tuổi trên 49 mạch nhâm hư, mạch xung suy, thiên quý kiệt, mạch thận không thông; nam giới trên 56 tuổi can khí suy kém, gân mạch yếu, thiên quý kiệt. Do vậy, ở lứa tuổi trên 50 chính khí của cơ thể giảm sút, vệ khí không còn vững chắc, ngoại tà phong hàn thấp thừa hư xâm nhập dễ dấn tới phát sinh bênh tật[2],[3], [4]...

Về giới, kết quả cho thấy $63,3 \%$ BN NNC và $60 \%$ BN NĐC là nữ giới, phù hợp với nhận định của nhiều tác giả[3],[5]... Các nghiên cứu đều cho rằng tỷ lệ nữ đau vùng cổ gáy do THCScó xu hướng nhiêu hơn nam do sự thay đổi hormone, đặc biệt sự thiếu hụt estrogen sau mãn kinh, mặt khác cũng có thể do phụ nữ có ý thức quan tâm tới sức khỏe bản thân hơn nên tới khám và điều trị ngay khi mới xuất hiện triệu chứng bệnh[1],[3],[5].

Về nghề nghiêp, kết quả nghiên cứu nhận thấy đối tượng mắc bệnh là lao động trí óc, hưu trí chiếm tỷ lệ cao, tuy nhiên đối tượng là lao động phổ thông cũng gặp ở $23,33 \%$ ở NNC và $20 \%$ ở NĐC, phù hợp với kết quả về độ tuổi mắc bệnh trong nghiên cứu cũng như nhận định của nhiều tác giả: đau vùng cổ gáy do THCS là một bệnh mạn tính xảy ra ở mọi thành phần của xã hội[1], [5]...

Về thời gian mắc bệnh, kết quả cho thấy $60 \%$ $B N$ NNC và $53,33 \%$ BN NĐC có thời gian mắc bênh từ 1 tới 3 tháng, phù hợp với nhân định của Nguyễn Tuyết Trang (2016), Nguyển Vinh Quốc (2017), Nguyễn Đức Minh (2018): trên 1/3 số $B N$ tới khám khi đã xuất hiện đau trên 1 tháng[3],[4], [5].

Tổn thương thường gặp nhất trên phim Xquang cột sông cổ các BN trong nghiên cứu là mất đường cong sinh lý, gai xương (bảng 1), phù hợp với kết quả nghiên cứu của Nguyê̂n Tuyết Trang (2016), Nguyễn Vinh Quốc (2017) 
cũng như một số tác giả khác[3],[5]. Điều cần lưu ý là những dấu hiệu Xquang ít có ý nghĩa về mặt bệnh học vì phần lớn không có dấu hiệu lâm sàng hoặc rất lâu sau này mới có triêuu chứng[1], nhiều trường hợp không nhận thẩy sự tương đồng giữa các triệu chứng lâm sàng với mức độ tổn thương trên phim Xquang. Vì vậy để chẩn đoán xác định đau vùng cổ gáy do THCS cần kết hợp linh hoạt giữa triệu chứng lâm sàng và hình ảnh tổn thương trên phim chụp Xquang $[1],[3],[5] \ldots$

4.2. Kết quả điêu trị. Trong THCS cổ, đau là triệu chứng chính khiến người bệnh phải tới khám, điều trị tại cơ sở y tế và VAS là thang điểm thông dụng để đánh giá mức độ đau được nhiều nghiên cứulựa chọn[1]. Kết quả cho thấy mức độ đau ở cả 2 nhóm BN đều được cải thiện sau điều trị, điểm VAS trung bình trước và sau điều trị khác biệt có ý nghĩa thống kê. VAS trung sau 20 ngày điều trị ở NNC tốt hơn có ý nghĩa so với NĐC. Hiệu quả giảm đau sau kết thúc liệu trình điều trị đánh giá ở mức độ tố tở NNC $(43,33 \%)$, cao hơn NĐC (20\%). Kết quả này cho thấycấy chỉ kết hợp chiếu đèn tần phổđã đạt hiệu quả giảm đau. Trên cơ sở tác dụng giãn cớ, cải thiện tuần hoàn tại vùng được tác động, giảm các triệu chứng viêm theo $Y$ học hiện đại và tác dụng khu phong, tán hàn, trừ thẩp, hành khí hoạt huyết chỉ thống theo YHCT, xoa bóp bấm huyệt kết hợp chiếu đèn tần phổ đã phát huy hiệu quả giảm đau đối với các $B N$ đau vùng cổ gáy do THCS thể can thận hư kết hợp phong hàn thấp[3],[4],[7]. Mặt khác kết hợp với tác động tại chố, phản ứng tiết đoạn và phản ứng toàn thân của cấy chỉ đã kích thích phản ứng cơ thể giảm hàm lượng Cathecholamin, tăng hàm lượng Achetylcholin và làm sản sinh Endorphin nội sinh, qua đó giúp tăng cường hiệu quả giảm đau[5], [6].

Hiệu quả giảm đau của phương pháp cấy chỉ kết hợp chiếu đèn tần phổ đã giúp cải thiện biên độ hoạt động cột sống cổ trên các BN NNC, tầm vận động cột sống cổ các động tác cúi, ngửa, nghiêng, xoay đều cải thiện có ý nghĩa so với trước điều trị. Hiệu quả cải thiện tầm vận động cột sống cổ sau 20 ngày điều trị đánh giá ở mức không hạn chế cao hơn NĐC. Kết quả này phù hợp với nhận định của nhiều nghiên cứu: hiệu quả cải thiện chức năng vận động cột sống cổ trên các BN đau vùng cố gáy do THCS tỷ lệ thuận với mức độ giảm đau[3],[4],[5]...

NDI là bộ công cụ đo đạc khách quan được nhiều nghiên cứu áp dụng để đánh giá ảnh hưởng của đau vùng cố gáy do THCS lên các chức năng sinh hoạt hàng ngày của người bệnh[1], [5]... Sau điều trị, NDI cải thiện có ý nghĩa qua các thời điểm đánh giá ở cả 2 nhóm $B N$. Điểm NDI trung bìnhsau 20 ngày điều trị ở NNC tốt hơn có ý nghĩa so với NĐC. Chức năng sinh hoạt đánh giá mức không hạn chế ở NNC $(33,33 \%)$, cao hơn so với NĐC (13,34\%). Như vậy, cấy chỉ kết hợp chiếu đèn tần phổđã góp phần nâng cao chất lượng sinh hoạt và hiệu suất lao động cho người bệnh. Đây cũng là nhận định của nhiêu tác giả - YHCT đạt hiệu quả tốt trong điêu trị các chứng đau mạn tính[3],[4], [5],[6].

Từ kết quả thay đổi điểm VAS, tầm vận động cột sống cổ, NDI, $90 \%$ BN ở NNC sau 20 ngày điều trị đạt kết quả tốt và khá, cao hơn NĐC $(73,33 \%)$. Có thể thấy cây chỉ kết hợp chiếu đèn tần phổ có tác dụng tốt đối với các BN đau vùng cổ gáy do THCS thể can thận hư kết hợp phong hàn thấp, kết quả này cũng phù hợp với lý luận YHCT về cơ chế tác dụng của kỹ thuật cấy chỉ cũng như chiếu đèn tần phổ[6], [7]. Trong quá trình thực hiện kỹ thuật chúng tôi không gặp tai biến nào, phương pháp không ảnh hưởng tới tần số mạch, chỉ số huyết áp trên cả 2 nhóm $B N$ nghiên cứu. Kết quả này cho thấy trình độ và năng lực của kỹ thuật viên 2 Bệnh việnkhi thực hiện các dịch vụ kỹ thuật chuyên ngành YHCT.

\section{KẾT LUẬN}

Cây chỉ kết hợp chiếu đèn tần phổhiệu quả tốt trong điều trị bệnh nhân đau vùng cổ gáy do thoái hóa cột sống. Tỷ lệ kết quả tốt và khá sau 20 ngày điều trị chiếm $90 \%$. VAS trung bình, điểm cải thiện chức năng sinh hoạt hàng ngày và biên độ hoạt động cột sống cổ sau điều trị đều được cải thiện có ý nghĩa so với thời điểm trước điều trị và tốt hơn so với nhóm đối chứng dùng xoa bóp bấm huyệt kết hợp chiếu đèn tần phổ.

\section{TÀI LIẸU THAM KHẢO}

1. Hồ Hữu Lương (2012). Thoái hóa cột sống cổ và thoát vị đĩa đệm, NXB Y học, Hà Nôi.

2. Bố Y tế (2020). Hội chứng cổ vai cánh tay. "Hi̛ướng dẫn chẩn đoán và điêuu trị bệnh theo y hợ cổ truyên, kết hợp y học cổ truyền với y học hiển đai". Ban hành kèm theo Quyết đinh số $5013 / Q \dot{Q}$ BYY ngày 01/12/2020 của Bộ trưởng Bộ Y tế, tập I, NXB Y hoc, Hà Nội, 37-43.

3. Nguyễn Vinh Quốc, Trịnh Thị Hạnh (2017): Đannh giá tác dụng điêu trị thoái hóa cột sống cổ bằng xoa bóp bẩm huyệt. Tạp chí $Y$ học thực hành, 12(1065), 20-22.

4. Nguyê̂n Đức Minh, Nguyễn Vinh Quốc (2018). Kết quả điều trị đau vai gáy do lannh bằng kỹ thuất ôn châm kết hợp xoa bóp bấm huy
dược lầm sàng 108, 5(13), 80-85.

5. Ngưuến Tuyết Trang, Đào Thị Phương (2016). Hiệu quả của phương pháp điện châm và cấy chỉ catgut trong điêu trị đau vai gáy do thoái hóa cột 
sống cổ. Tạp chí nghiên cứu Y học, 103(5), 17-23.

6. Lê Thúy Oanh (2010). Cãy chỉ, NXB Y hoc, Hà Nôi.

7. Hoc viện Quân y - Bộ môn vật lý trị liệu và Phục hổi chức năng (2014). Vất lý tri liêu và Phục hồi chức năng, NXB Quân đội nhân dân, Hà Nội.
8. Bộ Y tế (2013): Quyết định số 792/QĐ-BYT ngày $12 / 3 / 2013$ Về viêc ban hành Hướng dấn Quy trình kỹ thuật khám bệnh, chữa bệnh chuyên ngành Châm cứu.

\title{
ĐẶC ĐIỂM LÂM SÀNG VÀ HÌNH ẢNH HỌC GÃY CộT SỐNG Cổ KIỂU GIỌT LÊ
}

\author{
Ngô Quang Hùng ${ }^{1}$, Vũ Văn Hoè ${ }^{2}$, Hà Kim Trung ${ }^{3}$, Nguyễn Thành Bắc ${ }^{2}$
}

\section{TÓM TẮT}

Mục tiêu: Mô tả một số đặc điểm lâm sàng, hình ảnh Xquang quy ước, cắt lớp vi tính (CLVT) và cộng hưởng từ (CHT) của gãy cột sống cổ kiểu giọt lệ do chấn thương. Phương pháp: Chúng tôi tiến hành nghiên cứu tiến cứu, mô tả lâm sàng có can thiệp không có nhóm chứng 43 BN gãy đốt sống cổ kiểu giọt lệ được phẫu thuật tại Bệnh viện Việt Đức và Bệnh viện Xanh Pôn từ tháng 1 năm 2016 - tháng 12 nắm 2019. Kết quả: Tỉ lệ nam/nữ là 4/1. Tuổi trung bình là 38,02 $\pm 12,56$ tuổi. Đau cổ (100\%) và đau kiểu rễ $(55,81 \%)$ là hai triệu chứng cơ năng thường gặp nhất. Phân loại tổn thương tuỳ theo thang điểm Á̀IA, nhóm $A(30,23 \%)$ và nhóm $D(27,91 \%)$ có tỉ lệ nhiều nhất. Tî lệ tổn thương thần kinh là $79,07 \%$. Phân loại hôi chứng tủy cổ theo thang điểm mJOA trước mồ, tỉ lệ tổn thương mức độ trung bình đến nặng chiếm $62,8 \%$. Tổn thương đốt sống C5 là thường gặp nhất chiếm 39,53\%. Chủ yếu tổn thương do cơ chể quá gập. Kết luận: Gãy đốt sống kiểu giọt lệ thường gặp ở nam giới độ tuổi lao động do tai nan lào đônng ngã cao và tai nan giao thông xe máy. Vị trí tổn thương hay gặp nhất là đốt sống $\mathrm{C5}$ và tổn thương theo cơ chể gập. Hình thái tổn thương trên CLVT và $\mathrm{CHT}$ có liên quan tới tổn thương thần kinh trên lâm sàng.

Tư khoá: vỡ đốt sống cổ kiểu giọt lệ, đặc điểm lâm sàng, đặc điểm hình ảnh học, tổn thương thần kinh.

\section{SUMMARY \\ CLINICAL AND IMAGING FEATURES OF CERVICAL TEARDROP FRACTURES}

Objectives: To describe clinical and imaging features of cervical teardrop fractures. Methods: We implemented a prospective non-controlled interventional study of 43 cervical teardrop fractures at Viet Duc University Hospital and Saint Paul Hospital from January 2016 to December 2019. Results: Maleto-female ratio was 4/1. Mean age was $38.02 \pm 12.56$ years. Neck pain $(100 \%)$ and radiculopathy $(55,81 \%)$

\footnotetext{
${ }^{1}$ Bệnh viện Xanh Pôn

²Bênh viện Quân Y 103

${ }^{3}$ Bềnh viền Đa khoa Quốc Tế Hải Phòng

Chịu trách nhiệm chính: Ngô Quang Hùng

Email: drhungpttk@gmail.com

Ngày nhận bài: 5.7.2021

Ngày phản biên khoa hoc: 30.8.2021

Ngày duyệt bài: 6.9.2021
}

were the most common symptoms. ASIA grade A and $D$ were the most prevalent. Neurological deficit occurred in $79,07 \%$. $62.7 \%$ of patients had mJOA score at severe and moderate stage. C5 fracture accounted for $39.53 \%$. Flexion teardrop fracture was the main mechanism. Conclusion: Cervical teardrop fractures usually occurred in working age man and the main cause were occupational and traffic accidents. Flexion teardrop fracture of $\mathrm{C5}$ was the most frequent. Pathognomonic features of CT and MRI were associated with neurological deficits.

Keywords: Cervical teardrop fractures, clinical features, imaging features, neurological deficits.

\section{I. ĐĂT VẤN ĐỀ}

Gãy đốt sống cổ kiểu giọt lệ (Cervical Teardrop Fracture, CTF), được mô tả đâu tiên bởi Schneider và Kahn (1956) [4] là tình trạng võ góc trước dưới của thân đốt sông cô. Có hai cơ chế gây gãy đốt sống cổ kiểu giọt lệ là: (1) cơ chế cổ gập quá mức và (2) cơ chế cổ ưỡn quá mức. Trên thế giới, tỉ lệ gãy đốt sống cổ kiểu giọt lệ găp khoảng 8,8-23\% (trung bình 13,8\%) [3]. Tại Việt Nam theo Hà Kim Trung (2005), thương tổn kiểu giọt lệ chiếm khoảng 8,1\% chấn thương cột sống cổ có tổn thương thần kinh [1].

Gãy đốt sống kiểu giọt lệ thường gây nên các triệu chứng lâm sàng nặng nề; tổn thương tủy sống hoàn toàn có thể gặp trong 38\% - 91\% các trường hợp [7]. Phần lớn là các tổn thương tủy sống không hoàn toàn, trong đó hội chứng tủy sống trước chiếm tới $80 \%$ [8]. Tổn thương thân kinh trong gãy đốt sống kiểu này phụ thuộc vào loại của tổn thương và vào sự di lệch của mảnh xương võ vào trong ống sống, vì vậy cân thiết phải mô tả đây đủ tổn thương dựa trên hình ảnh cắt lớp vi tính và cộng hưởng từ cột sống cổ.

Hiện nay trên thế giới có nhiều nghiên cứu mô tả về hình thái và đặc điểm lâm sàng của gãy đốt sống kiểu giọt lệ. Các tác giả đều nhận định rằng cơ chế chấn thương, hình thái tổn thương đốt sông, và mức độ tổn thương thân kinh là những yếu tố tiên lượng quan trọng $[5,6]$. Tại Việt Nam, tác giả Phan Thanh Hào năm 2012 cũng đã mô tả 39 bệnh nhân võ̃ đốt sống kiểu 